\title{
Super-Items Created by Mere Presence of Visual Material on Retail Displays
}

\author{
Salvatore Saiu ${ }^{1}$, Francesco Massara ${ }^{2}, \&$ Daniele Porcheddu ${ }^{3}$ \\ ${ }^{1}$ Department of Agriculture, University of Sassari, Italy \\ ${ }^{2}$ Department of Business, Università IULM, Italy \\ ${ }^{3}$ Department of Economics and Business, University of Sassari, Italy \\ Correspondence: Salvatore Saiu, Department of Agriculture, University of Sassari, Viale Italia 39, 07100 Sassari, \\ Italy.
}

Received: February 26, 2020

Accepted: March 27, 2020

Online Published: April 2, 2020

doi:10.5539/ibr.v13n5p1

URL: https://doi.org/10.5539/ibr.v13n5p1

\begin{abstract}
This study focuses on the perception of numerosity of item sets placed in retail displays. Previous studies have demonstrated that the item sets' perceived numerosity decreases as the number of polygonal shapes placed in a panel behind a display increases. Such a result was explained by a non-spatial clustering phenomenon exerted by the shapes. Our research reveals the perceptual mechanisms underlying the described effect. Using an eye-tracking procedure, we highlight that upon augmenting the number of polygonal shapes in the decision-making context: (a) there is a significant decrease in the number of total fixations per display; (b) there is an underestimation of the perceived numerosity of item sets involved. The findings suggest that the mere presence of visual shapes can alter perception generating complex objects or "super-items", which tend to perceptually replace entire item sets. We also propose managerial implications in terms of category management and merchandising.
\end{abstract}

Keywords: category management, merchandising, eye-tracking technology, retailing, shelf-based scarcity.

\section{Introduction}

The present study aims at analyzing the numerosity perception of item sets placed in retail displays. Previous research showed that the relative numerosity perception of item sets on a display decreases by increasing the number of polygonal shapes placed on a panel behind the same display (see Porcheddu and Pinna, 2015). This underestimation effect has been hypothesized as the creation of perceptual super-items that "replaces" the item sets involved, however, we do not know what are the perceptual mechanisms underlying such an effect. Based on a lab experiment on eye-tracking, this research aims at empirically finding the existence of super-items, shedding light on the details of the perceptual process involved. In fact, although eye tracking procedures still represent a niche in consumer behavior studies, previous research has shown that eye tracking data provides reliable measures of attention to stimuli in complex scenes such as retail displays (Chandon et al., 2009).

\section{Literature Review}

Koesling and colleagues (2004) highlighted a phenomenon of numerosity underestimation concerning dot-like item sets provided with "additional information" in terms of randomly arranged polygonal shapes. They explained their findings in terms of a "masking effect": each polygon inserted into the decisional context perceptually "replaced" the items located inside it, as if it was perceptually "hiding" them. Consequently, the evaluation of the numerosity of the examined set with the polygons resulted inferior respect to the set without additional information. An extension of Koesling et al.'s analysis $(2004 ; 1998)$ on the comparison of realistic sets of products on simulated retail displays has been recently proposed by Porcheddu and Pinna (2015). Per them, the placement of polygonal shapes inside the decisional field leads to the emergence of perceptual super-items that significantly influence the perception of numerosity. Using as a reference the experiments of Ponzo (1928), Porcheddu e Pinna (2015, p.373) extended their applicability to non-spatial clustering introducing the notion of "super-item" or "higher level item". Ponzo had hypothesized a spatial clustering effect and the existence of a superior level group unit in which each single item "loses" part of its individuality and independence to "congregate" into a (superior) collective entity (see Ponzo, 1928, pp.16-17). To illustrate the depressive effect, in 
Figure 1 we show, by way of illustration, a hypothetical comparison between two sets of wine bottles. In the upper part of the Figure 1 there is a set of wine bottles arranged to form groups, while, at the bottom, bottles are arranged homogeneously along an imaginary line. Wine bottles arranged in clusters tend to appear less numerous than homogeneously distributed, even if this is not objectively true (in fact, the number of bottles is identical, as is the length of the segment on which they are arranged) (see. Saiu, 2017; Porcheddu and Massara, 2015).
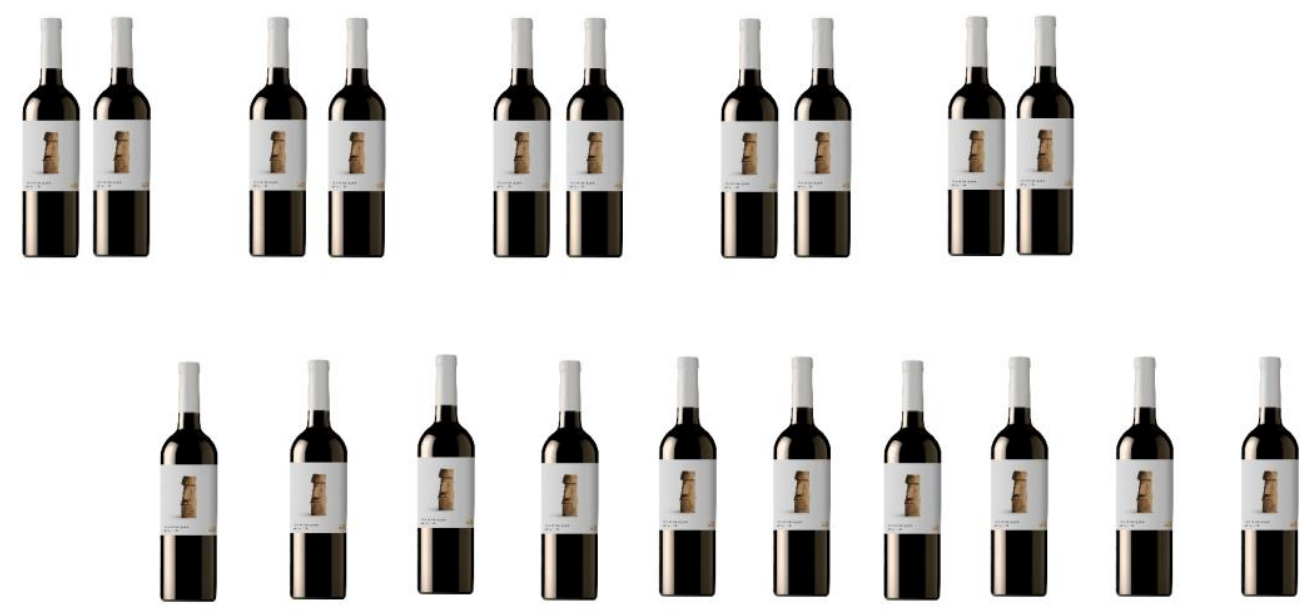

Figure 1. The spatial clustering effect (Adaptated from Saiu, 2017)

Porcheddu and Pinna (2015), using some of the experiments suggested by Koesling et al. (2004; 1998), observe that the agglomeration of items occurs because the items belong to (or are contained into) the same "additional" structure (in this specific case a polygonal structure). Figure 2 shows how polygons can form a non-spatial agglomeration (i.e., not based on objective spatial distance) with respect to circumscribed dots. To exemplify, while the dots A and B are visually part of the same cluster, this does not happen for the dot $\mathrm{C}$, although it is closer to B than $\mathrm{A})^{1}$.

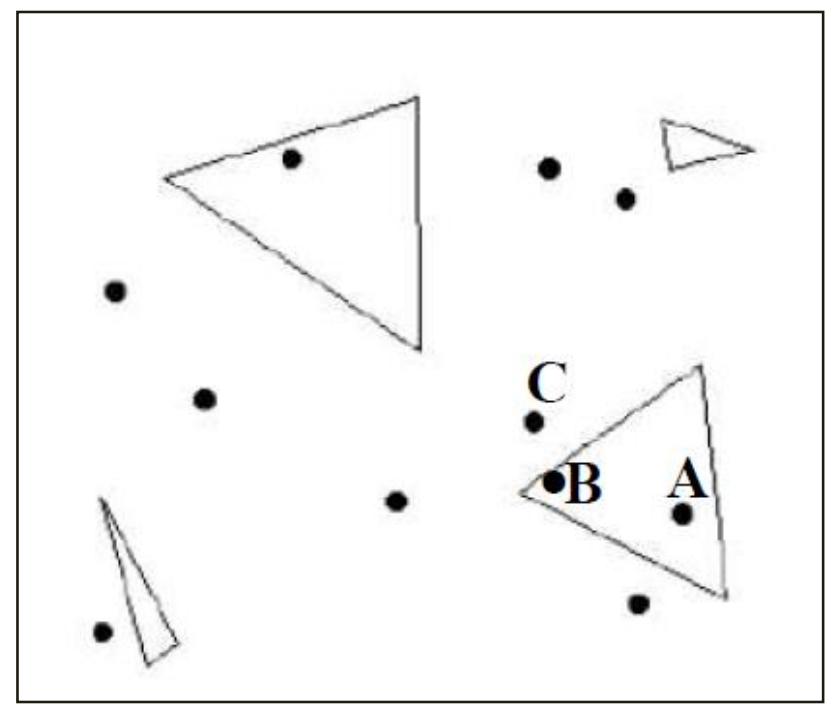

Figure 2. An example of non-spatial clustering (Adaptated from Koesling et al., 1998)

\footnotetext{
${ }^{1}$ We can mention further non-spatial clustering mechanisms such as that based on the different color of the items (Redden and Hoch, 2009; Frith and Frith, 1972; Porcheddu and Pinna, 2015).
} 
Although the above mentioned studies refer to a "higher level unit" (Ponzo, 1928) and "super-item" (Porcheddu and Pinna, 2015), respectively, the cited authors limited their studies to the perceptual "conditioning" effects on the evaluation of relative numerosity presumably exerted by these entities, without producing any additional evidence. According to Goldberg and Kotval (1999), the number of fixations is positively correlated to the number of components/items processed by the observer. The potential reduction in fixation points, which may occur with the insertion of polygonal shapes, would suggest a simplification of the overall perception process and of the resulting enumeration task. Basically, it is as if visual perception would become more efficient or simplified thanks to the mere presence of visual material whose informativity is implicitly induced by the observer. On the other hand, when no simplifiers are introduced there should be a high number of visual fixations, implying that the decision maker should "sample" from the visual display a high number of items to fulfil the assigned task (as if he/she was "distracted" or "limited" while carrying out his/her task, see Goldberg and Kotval, 1999). Basically, a lower number of fixations in a setting with polygonal shapes shows that the selective attention is at work synthetizing information. Due to this fact, the perception process becomes more efficient reducing the need for cognitive resources. The opposite, on the other hand, seems to occur in the case of patterns free from additional information. Thus, the mere presence of polygonal shapes seems to improve visual search efficiency (see Goldberg and Kotval, 1999; 1998; also Kotval and Goldberg, 1998), while the contrary happens in displays free from polygonal shapes.

Based on the cited literature, the following hypothesis is formulated:

Hp.1: given an approximate enumeration task of a comparative type set up for item sets having identical numerosity, the number of fixations involving each display tends to decrease with the increase of the number of polygonal shapes introduced in the visual context.

Moreover, we expect results consistent with this empirical hypothesis:

Hp.2: results expected in Hpl are independent by the polygonal shape adopted.

\section{Materials and Methods}

One hundred and sixty university students were enrolled in the present study as volunteers ${ }^{2}$. Based on anamnesis, inclusion criteria were: 1) normal visual acuity (natural or o corrected by using corneal lenses); 2) no history of ophthalmological or neurological disorders. Once carried out the postural protocol and after having completed the procedure to set-up an eye-tracking device (Gazepoint ${ }^{\circledR}$ GP3 $)^{3}$, each subject was exposed to visual stimulation according to a free-viewing approach (Nicholls et al., 1999). Specifically, a 17.3" HD+ antireflet 1920x 1080 pixels at $48 \mathrm{~Hz}$ portable monitor was placed on the desk, $100 \mathrm{~cm}$ away from the subjects. Each participant, from a sitting position, was asked to observe an image on the screen. Images were casually extracted from a database and showed a set of three retail displays placed side-by-side, partially completed, frontally seen and characterized by 5 shelves, where up to 200 items could be placed in total (see Figure 3$)^{5}$.
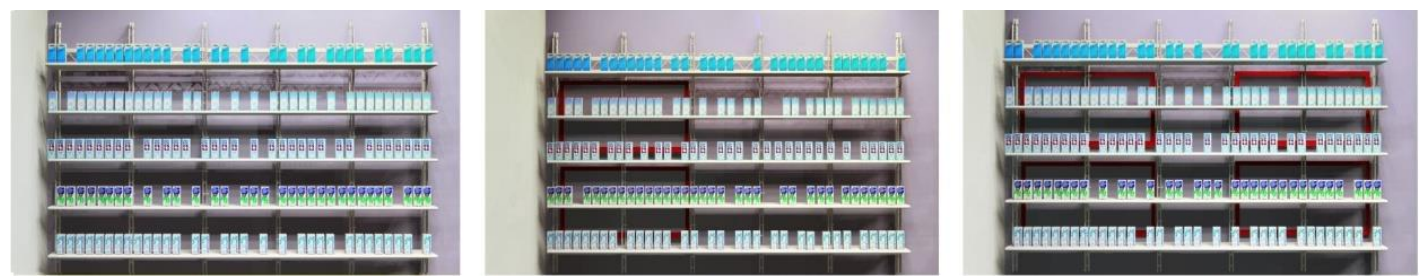

Figure 3. Example of the stimuli used during the experiment.

\footnotetext{
${ }^{2}$ Considering the statistical test we run in our study, the necessary sample size to detect a medium effect size (at power $=0.80$ for $\alpha=0.05$ ) is between 120 and 140 (see Clark-Carter, 2004, p. 603).

${ }^{3}$ Once the subject was seated in front of the monitor, as per best practice, we have begun the eye tracker's calibration procedure. For each subject, the calibration session is different; the device adapts to the participant's face morphological features and peripheral organs of sight.

${ }^{4}$ According to this approach, the same stimulus jointly involves both participant's visual hemifields and therefore affects both his/her cerebral hemispheres (Porcheddu et al., 2011).

${ }^{5}$ We created a set of 160 high resolution coloured images, with size $1920 \times 1080$ pixels, 2540 dpi resolution, through the support of the graphic design software (3-D Google Sketchup Pro, version 8.0). All the images were subsequently rendered.
} 
In Figure 3, the number of polygons placed on the back panel increases from left to right.

In order to ensure that displays had an elevated similarity to real life, we showed images of UHT milk cartons with the packaging of five brands really existing on the market, placed on the shelves according a horizontal "brand blocking" logic (Young, 2005). Figure 4 shows in detail one of the images used during our study. An elevated degree of similarity to real products can be noticed.

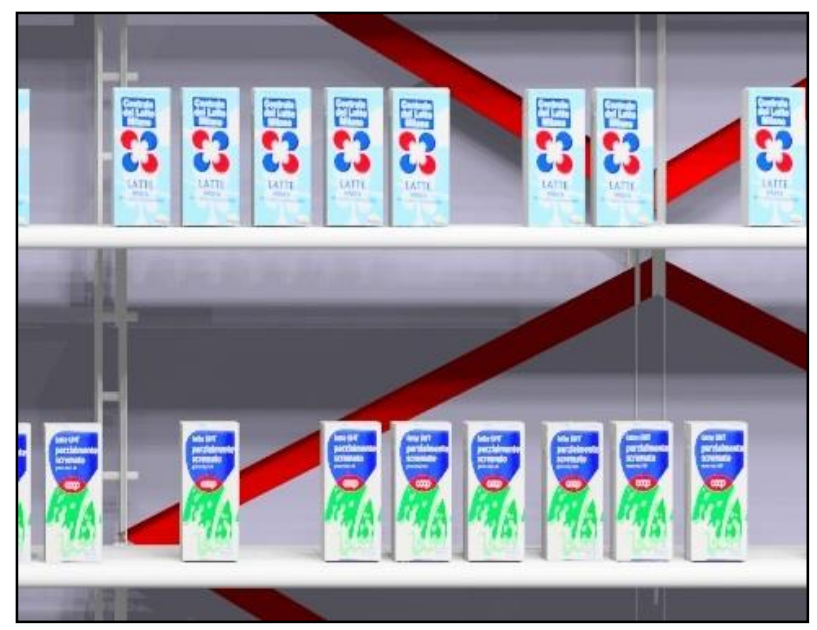

Figure 4. A close-up view of one of the images used during the experiment

The three displays were characterized by the same degree of "incompleteness" (equal to the $20 \%$ of the total products that potentially could be stocked) and by a randomized distribution of items on the shelves. Visual stimuli resulted from the a computer application based on Java. We first generated 10 casual vectors consisting of 160 numbers each; in fact, the number of products placed on each display had to be equal to 160 , having selected an incompleteness degree of $20 \%$ on a total of 200 products that could potentially fill up the shelves. The use of random vectors and, therefore, of random empty shelf positions on the displays, was functional to randomly distribute possible effects deriving from the qualitative characteristics of the distribution of the missing items (Akin e Chase, 1977). Going into more detail, the casual vectors had the following characteristics: 1) numbers inside the series were positive integers different between each other; 2) their value was included between 1 and 200 and univocally expressed a specific position - along the vertical/horizontal dimension inside the display where the item was going to be placed. From each casual vector were obtained: 1) a display without any additional information on the panel behind the shelves; 2) a display with a panel characterized by the placement of two rectangles or two rhombuses; 3 ) a display with four polygons having total sizes identical to the rectangles/rhombuses of the previous configuration. Based on this system, 30 different displays were created, grouped in 3 different families: 10 displays without polygonal shapes; 10 displays with two shapes (i.e. displays showing two rectangles/rhombuses); 10 displays with four shapes (i.e. displays with four rectangles/rhombuses placed on the panel at the back of the display). Starting with these 30 displays, we generated an elevated number of combinations of displays in sets of three. More precisely, one hundred and sixty stimuli were created: a set of 80 images contained additional information in the form of rectangles, the remaining 80 images had rhomboid stimuli. We carefully selected the display from each family, avoiding that two or more displays were derived from the same casual vector. Each group of three displays was formed by displays having the following characteristics: 1) one did not show any additional information; 2) one was characterized by polygonal forms placed on the panel at the back (two rectangles or two rhombuses); and, 3) one display was characterized by four rectangles (or rhombuses). The position of the three displays relative to the observer was also randomized. Each visual stimulus persisted on the screen for 30 seconds and the fixation points pattern was recorded by the eye-tracker (see in Figure 5 the output of one of the individual sessions). Each participant's task was to rank, without counting the number of items, the three-displays based on the ascending order of items located on shelves, thus starting from the display which was believed to contain the lower number of items.

The order based on relative numerosity was verbally communicated to the supervisor and it was meant to involve all items on each display. 


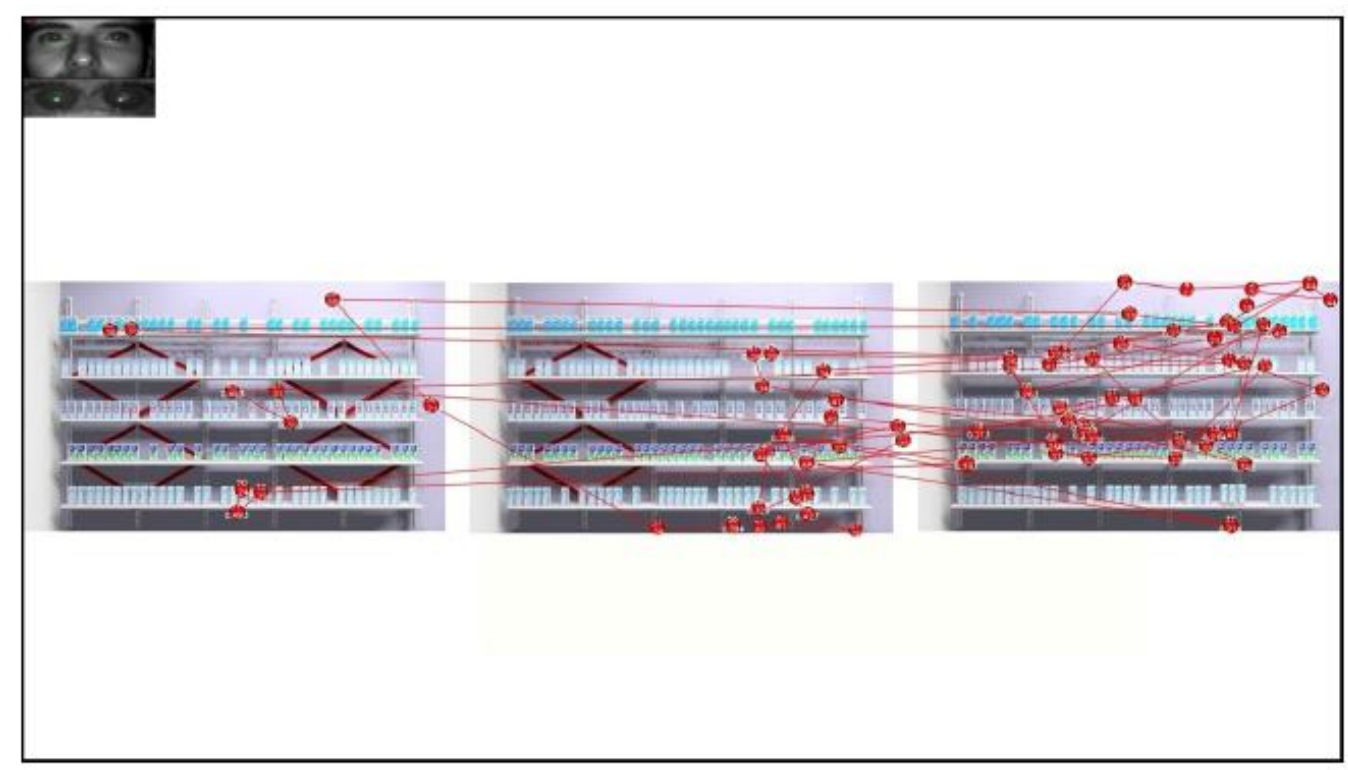

Figure 5. A combined three-display set showing rhombus-shaped additional information and relative fixation map recorded during one of the individual experimental sessions

Statistical analysis was performed through a two-factor mixed factorial ANOVA. The experimental design was: POLYGONS $\times$ SHAPE. In detail, POLYGONS (i.e., Polygons Quantity) as within-subjects factor, based on three levels: 1) no polygons; 2) two polygons; 3) four polygons; while, SHAPE (i.e., Type of Polygonal Shape) as between-subjects factor, indicated by the polygonal-shape used. Shape was varied using: 1) rectangular polygons for half of the experimental sample; 2 ) rhomboidal polygons for the rest of the sample.

\section{Results}

One hundred and sixty subjects (equally distributed between the genders) (total mean age $=24.58$ years; $\mathrm{SD}=5.69$ ) were enrolled into the study.

R1: The inferential analysis on distribution of fixation points on displays, based on a two-factor mixed ANOVA, highlighted that the POLYGONS factor is significant beyond $0.01\left[\mathrm{~F}(2,316)=76.896 ; \mathrm{p}<0.01 ;\right.$ partial $\eta^{2}=.327$, i.e. a large effect (see Cohen, 1988)]. Conversely, the SHAPE factor is not significant $[\mathrm{F}(1,158)=0.010$; ns $]$. Likewise, the POLYGONS $\times$ SHAPE interaction was not statistically significant $[\mathrm{F}(2,316)=0.387$; ns $]$. The post hoc tests on POLYGONS, based on the Bonferroni method, highlighted statistically significant differences in any pairwise comparisons. Specifically, it has been observed: a) a significant reduction of the average number of fixations recorded respect to the four polygons conditions, both respect to two polygons $(\mathrm{p}<0.001)$ and in the context free of polygonal shapes $(\mathrm{p}<0.001)$; $\mathrm{b}$ ) a significant decrease of the average number of fixations recorded in the two polygonal shapes respect to the context free from polygonal shapes $(\mathrm{p}<0.001)$.

R2: We carried out a non-parametric statistical analysis on the explicit ranking formulated by participants in terms of ascending relative numerosity of items displayed on the compared displays. Specifically, the null hypothesis on equality of mean ranks associated to the three levels of polygonal shapes $(4,2$ and 0 ) has been rejected based on a Page's Ordered Alternative Test (Page, 1963; Sawilowsky and Fahoome, 2005; Gibbons and Chakraborti, 2003). The alternative hypothesis was the descending monotonic tendency of central trends (in this case: the mean ranks) while increasing the amount of polygons placed in the visual display $[\mathrm{L}=2058 ; \mathrm{p}<0.01$; effect size measure (i.e. standardized L; cf. Peng and Chen, 2015): Ls=7.71; 95\% CI for Standardized $\mathrm{L}=7.71 \pm 1.96=(5.75,9.67)]$.

\section{Discussion}

R1 results are consistent with $\mathrm{H} 1$ and $\mathrm{H} 2$ formulated in section 3: the number of fixations by observer tends to decrease with the increase in the amount of polygonal shapes placed into the visual context and this result is independent by the type of shape on the display.

The lower number of fixations in contexts characterized by the presence of polygonal shapes supports the idea 
that the selective visual attention performs a non-spatial clustering process (as mentioned into section 2 above) creating "super-items". Due to this fact, visual search seems to be more efficient. The opposite seems to occur in the case of patterns/displays free of polygonal shapes.

The "simplification" that occurs during the visual stimulation tested by the present study empirically demonstrate the existence of super-items, or non-spatial clusters, "enclosed" within the polygonal shapes that we used as additional information in the experimental setting. The results lend support to the reduced perceived numerosity of item sets placed on displays, when the amount of polygonal shapes introduced into the visual setting increases. This result had already been reported in the literature (see Porcheddu and Pinna, 2015) and it is here confirmed by the analysis of "explicit" ranking generated during our experiment (see above R2 results).

\section{Managerial Implications}

We reckon that the results shown above provide a better understanding of a perceptual phenomenon that has several managerial implications for merchandising and category management.

Our findings highlight that perception of items stocked on supermarket shelves can be "conditioned" through the introduction of polygonal shapes on the display. The mere presence of such shapes generates a grouping illusion of the items enclosed within the boundaries of the shape. We also find that the effect increases with the number of polygons introduced in the display.

It should be noted that, in the retailing field, the polygonal figures such as those used in this study can be classified in the "universe" of POP material (Buttle, 1984).

The polygonal figures could, therefore, be placed in correspondence of a set of items to reduce their perceived numerosity, compared to neighboring item sets, with the likely result to produce a shelf-based scarcity effect promoting their sales. In effect, as it has already been highlighted by the shelf-based scarcity literature, through laboratory and field experiments (see Usai et al., 2018; Hatton-Jones et al., 2017; Robinson et al., 2016; Massara et al., 2014; Porcheddu, 2013; Parker and Lehmann, 2011; van Herpen et al., 2009; Razzouk et al., 2002), there is a link between shelf-based scarcity and consumer preferences. The studies just mentioned have shown that customers tend to choose products characterized by a greater relative shelf-scarcity (i.e. relatively less numerous items). The phenomenon is explained by referring mainly to the so-called Bandwagon Effect Theory (Corneo and Jeanne, 1997), which postulates that, in certain conditions, people purchase products by letting themselves be guided by the other clients' preferences. These preferences may result from peer observation at the point of purchase (Baxendale et al., 2015) or they can be inferred by the choices of other customers traced on the basis of empty shelf-positions on the displays.

Therefore, retailers could use the polygonal shapes to increase the sales of one subcategory compared to the others, and, within a subcategory, to increase the sales of some brands respect to others. Presumably retailers could use the super-item logic to benefit private labels over national brands.

\section{Limitations and Suggestions for Future Research}

In this study, we show that perception of numerosity may be altered by mere presence of visual material, providing solid evidence with eye-tracking data that the number of fixations diminishes as the amount of additional visual information - in terms of polygonal shapes - on a display increases. While the finding per se is interesting, it says nothing respect to the effects that it may have on the final choice, therefore whether the mentioned shelf-based scarcity effect may truly occur, is for the moment just a speculation. Additional studies may investigate outcome variables such as choice and satisfaction with choice, which have already been investigated in mere effects literature concerning the perception of grouping and categories (Molginer et al., 2008).

We cannot exclude the possibility that the experimental nature of our research and the lack of representativeness of the sample with respect to the entirety of those who everyday makes use of modern retail outlets, reduce the external validity of the results.

Future research using more representative samples could support the robustness of our results in more realistic laboratory situations, or even in real stores.

\section{Ethical Aspects}

There was no financial interest whatsoever in any material used or result obtained in this research. We did not appeal the local Bioethics committee since the experiments involved healthy subjects in non-invasive procedures. All participants received detailed information and gave written consent for participation in the experiment in accordance with the declaration of Helsinki (see e.g. World Medical Association, 2015). No compensation was offered to the subjects. From an ethical point of view, we suggest that retailers may explicitly indicate the use of 
additional information as in our study (in fact, only a negligible number of participants - overall less than 5\% reported verbally, at the end of the experimental task, the presence of the polygonal figures placed behind the items).

\section{References}

Akin, O., \& Chase W. (1977). Quantification of three-dimensional structures. Journal of Experimental Psychology: Human Perception and Performance, 4(3), 397-410. https://doi.org/10.1037/0096-1523.4.3.397

Baxendale, S., Macdonald, E. K., \& Wilson, H. N. (2015). The impact of different touchpoints on brand consideration. Journal of Retailing, 91(2), 235-253. https://doi.org/10.1016/j.jretai.2014.12.008

Buttle, F. (1984). Merchandising, European Journal of Marketing, 18(6/7), 104-123. https://doi.org/10.1108/EUM0000000004795

Chandon, P., Hutchinson, J. W., Bradlow E. T., \& Young, S. H. (2009). Does In-Store Marketing Work? Effects of the Number and Position of Shelf Facings on Attention and Evaluation at the Point of Purchase. Journal of Marketing, 73(6), 1-17. https://doi.org/10.1509/jmkg.73.6.1

Clark-Carter D. (2004). Quantitative Psychological Research: A Student's Handbook (2nd ed.). Psychological Press, Hove and New York.

Cohen, J. (1988). Statistical power analysis for the behavioral sciences (2nd ed.). Lawrence Erlbaum Associates, Hillsdale (NJ).

Corneo, G., \& Jeanne, O. (1997). Snobs, Bandwagons, and the Origin of Social Customs in Consumer Behaviour. Journal of Economic Behavior \& Organization, 32(3), 333-347. https://doi.org/10.1016/S0167-2681(96)00024-8

Frith, C. D., \& Frith, U. (1972). The solitaire illusion: An illusion of numerosity. Perception \& Psychophysics, 11(6), 409-410. https://doi.org/10.3758/BF03206279

Gibbons, J. D., \& Chakraborti, S. (2003). Nonparametric statistical inference (4th ed.). Marcel Dekker, New York.

Goldberg, J. H., \& Kotval, X. P. (1998). Eye movement-based evaluation of the computer interface. Advances in Occupational Ergonomics and Safety, ISO Press. Amsterdam, pp.529-532.

Goldberg, J. H., \& Kotval, X. P. (1999). Computer interface evaluation using eye movements: Methods and constructs. International Journal of Industrial Ergonomics, 24(6), 631-645. https://doi.org/10.1016/S0169-8141(98)00068-7

Hatton-Jones, S., Teah, M., Cheah, I., \& Phau, I. (2017). Perceived scarcity and shelf organisation: a case of luxury chocolate. In P. Rossi (Ed.), Marketing at the confluence between entertainment and analytics, pp. 833-838, Springer, Berlin. https://doi.org/10.1007/978-3-319-47331-4_165

Koesling, H., Carbone, E., Pomplun, M., Sichelschmidt, L., \& Ritter, H. (2004). When more seems less-non-spatial clustering in numerosity estimation. Proceedings of the Early Cognitive Vision Workshop, May 28-June 1, 2004. Isle of Skye, Scotland.

Koesling, H., Pomplun, M., \& Ritter, H. (1998). The effects of structural information on perceived numerosity in two-dimensional object distributions. CRC 360 Technical Report 2/1998, pp. 9-15, University of Bielefeld (Germany). Retrieved from https://pub.uni-bielefeld.de/record/2714967

Kotval, X. P., \& Goldberg, J. H. (1998). Eye movements and interface components grouping: an evaluation method. Proceedings of the 42nd Annual Meeting of the Human Factors and Ergonomics Society, Human Factors and Ergonomics Society, Santa Monica (CA), pp. 486-490. https://doi.org/10.1177/154193129804200509

Massara, F., Porcheddu, D., \& Melara, R. D. (2014). Asymmetric Perception of Sparse Shelves in Retail Displays. Journal of Retailing, 90(3), 321-331. https://doi.org/10.1016/j.jretai.2014.05.001

Mogilner, C., Rudnick, T., \& Iyengar, S. S. (2008). The mere categorization effect: How the presence of categories increases choosers' perceptions of assortment variety and outcome satisfaction. Journal of Consumer Research, 35(2), 202-215. https://doi.org/10.1086/588698

Nicholls, M. E. R., Bradshaw, J. L., \& Mattingley, J. B. (1999). Free-viewing perceptual asymmetries for the judgement of brightness, numerosity and size. Neuropsychologia, 37(3), 307-314.

https://doi.org/10.1016/S0028-3932(98)00074-8 
Page, E. B. (1963). Ordered hypotheses for multiple treatments. A significance test for linear ranks. Journal of the American Statistical Association, 58(301), 216-230. https://doi.org/10.1080/01621459.1963.10500843

Parker, J. R., \& Lehmann, D. R. (2011). When Shelf-Based Scarcity Impacts Consumer Preferences. Journal of Retailing, 87(2), 142-155. https://doi.org/10.1016/j.jretai.2011.02.001

Peng, C. Y. J., \& Chen, L. T. (2015). Algorithms for Assessing Intervention Effects in Single-Case Studies. Journal of Modern Applied Statistical Methods, 14(1), 276-307. https://doi.org/10.22237/jmasm/1430454060

Ponzo, M. (1928). Illusioni negli apprezzamenti di collettività (Illusions in the appreciation of groups). Archivio Italiano di Psicologia, 7, 1-37.

Porcheddu, D. (2013). Come percepiamo i display incompleti nei punti vendita? (How do we perceive incomplete displays in retail outlets?). Mercati e Competitività, 10(4), 59-81. https://doi.org/10.3280/MC2013-004004

Porcheddu, D., \& Massara, F. (2015). Disposizione dei prodotti a scaffale e percezione di numerosità. I risultati di uno studio esplorativo (Arrangement of products on display and perception of numerosity. Some results from an exploratory study). Micro \& Macro Marketing, 24(1), 85-105.

Porcheddu, D., \& Pinna, B. (2015). Informazioni addizionali sui display e percezione della scarsità relativa dei prodotti a scaffale (Additional information on displays and shelf-based scarcity perception). Micro e Macro Marketing, 24(3), 369-392.

Porcheddu, D., Usai, A., \& Venturi, A. (2011). Nonverbal stimuli in a virtual aisle: does the shelf you choose matter? International Review of Retail, Distribution \& Consumer Research, 21(3), 215-231. https://doi.org/10.1080/09593969.2011.578797

Razzouk, N. Y., Seitz, V., \& Kumar, V. (2002). The impact of perceived display completeness/incompleteness on shoppers' in-store selection of merchandise: an empirical study. Journal of Retailing and Consumer Services, 9(1), 31-35. https://doi.org/10.1016/S0969-6989(01)00008-X

Redden, J. P., \& Hoch, S. J. (2009). The presence of variety reduces perceived quantity. Journal of Consumer Research, 36(3), 406-417. https://doi.org/10.1086/598971

Robinson, S. G., Brady, M. K., Lemon, K. N., \& Giebelhausen, M. (2016). Less of this one? I'll take it: New insights on the influence of shelf-based scarcity. International Journal of Research in Marketing, 33(4), 961-965. https://doi.org/10.1016/j.ijresmar.2016.03.005

Saiu, S. (2017). Aspetti della percezione della shelf-based scarcity nell'ambito del grocery (Some aspects of the perception of shelf-based scarcity in the grocery stores (Doctoral dissertation, University of Sassari, Italy). Retrieved from https://core.ac.uk/display/84318575

Sawilowsky, S., \& Fahoome, G. (2005). Page's Ordered Alternatives Test. In B. S. Everitt \& D. C. Howell (Eds.), Encyclopedia of Statistics in Behavioral Science, Vol. 3, pp. 1503-1504, John Wiley \& Sons, New York. https://doi.org/10.1002/0470013192.bsa464

Söderlund, M. (2011). Other customers in the retail environment and their impact on the customer's evaluation of the retailer. Journal of Retailing and Consumer Services, 18(3), 174-182. https://doi.org/10.1016/j.jretconser.2010.09.006

Usai, A., Porcheddu, D., Scuotto, V., \& Susini, J. P. (2018). Converting Shelf-Based Scarcity into Innovation by Adopting Customer-Focused Innovation Approach. Journal of the Knowledge Economy (online first). https://doi.org/10.1007/s13132-018-0536-y

van Herpen, E., Pieters, R., \& Zeelenberg, M. (2009). When Demand Accelerates Demand: Trailing the Bandwagon. Journal of Consumer Psychology, 19(3), 302-312. https://doi.org/10.1016/j.jcps.2009.01.001

World Medical Association. (2015). Medical Ethics Manual (3rd ed.). The World Medical Association: Ferney-Voltaire Cedex, France.

Young, S. (2005). Breaking through the clutter. Package Design, July-August, pp. 58-61.

\section{Copyrights}

Copyright for this article is retained by the author(s), with first publication rights granted to the journal.

This is an open-access article distributed under the terms and conditions of the Creative Commons Attribution license (http://creativecommons.org/licenses/by/4.0/). 